\title{
CONECTIVIDADE E CONEXÃO NOS PROCESSOS PARTICIPATIVOS: NOVAS TECNOLOGIAS E VELHOS PROBLEMAS
}

\section{CONNECTIVITY AND CONNECTION IN PARTICIPATORY PROCESSES: NEW TECHNOLOGIES AND OLD PROBLEMS}

\author{
Vítor Domício de Meneses ${ }^{1}$, Daniel Ribeiro Cardoso ${ }^{1}$
}

\section{RESUMO:}

O planejamento da cidade contempla uma reflexão sobre quais caminhos de desenvolvimento são desejados e como os problemas existentes podem ser resolvidos, tendo como condição essencial a participação popular. As Tecnologias de Informação e Comunicação (TICs) apresentam grandes transformações em diversos setores da sociedade e, sobretudo, inauguram novos canais de comunicação e novas formas de participação através de ambientes virtuais. Este trabalho tem como objetivos realizar um levantamento de dispositivos virtuais de participação para analisar sua utilização nos processos participativos contemporâneos e identificar e sistematizar os principais problemas destes processos. Para atingir os objetivos propostos, são analisados e classificados seis dispositivos virtuais de participação mediante os tipos de conexão que estabelecem com os usuários e, para refletir sobre sua utilização, são investigadas os entraves dos processos participativos contemporâneos, sistematizando-os como problemas da ferramenta, problemas do processo e problemas do cidadão. Entre as problemáticas apontadas estão a exclusão digital, a falta de legitimidade das redes, a vontade política, a desigualdade social e a falta de engajamento político dos cidadãos. Os resultados da pesquisa demonstram que os dispositivos de participação constituem novos processos, mas não solucionam os problemas dos processos tradicionais, trazem novas possibilidades para participação ao mesmo tempo que adicionam maior complexidade ao processo.

PALAVRAS-CHAVE: Tecnologias de Informação e Comunicação; Processos Participativos; Planejamento urbano.

\begin{abstract}
:
The planning of the city includes a reflection on which development paths are desired and how existing problems can be solved, with popular participation as an essential condition. Information and Communication Technologies (ICTS) have undergone major changes in various sectors of society and, above all, have opened new communication channels and new forms of participation through virtual environments. This work aims to carry out a survey of virtual participation devices to analyze their use in contemporary participatory processes and to identify and systematize the main problems of contemporary participatory processes. To achieve the proposed objectives, six virtual participation devices are analyzed and classified through the types of connection they establish with users and, to reflect on their use, the barriers of contemporary participatory processes are investigated, systematizing them as problems of the tool, process problems and citizen problems. Among the issues pointed out are the digital exclusion, the lack of legitimacy of networks, political will, social inequality and the lack of political engagement by citizens. The results of the research demonstrate that the participation devices constitute new processes, but do not solve the problems of traditional processes, they bring new possibilities for participation while adding more complexity to the process.
\end{abstract}

KEYWORDS: Information and Communication Technologies; Participatory processes; Urban planning

How to cite this article:

MENESES, V. D.; CARDOSO, D.R. Conectividade e conexão nos processos participativos: novas tecnologias e velhos problemas. Gestão \& Tecnologia de Projetos. São Carlos, v15, n3, 2020.

https://doi.org/10.11606/gtp.v15i3.166833
Fonte de Financiamento: Fundação Cearense de Apoio ao Desenvolvimento Científico e Tecnológico FUNCAP

Conflito de Interesse: Declara não haver.

Submetido em: 17/02/2020 Aceito em: 08/07/2020
${ }^{1}$ Universidade Federal do Ceará - UFC 


\section{INTRODUÇÃO: A PROBLEMÁTICA DA PARTICIPAÇÃO}

Desde o surgimento da cidade até os dias atuais, grandes transformações ocorreram para que os primitivos agrupamentos humanos se convertessem em grandes metrópoles, adicionando complexidade ao território e acarretando diversos problemas de ordem infraestrutural, social e política. A ideia de cidade como um produto de todos os cidadãos ampara-se em uma dimensão coletiva, pressupondo ações que objetivem o bem comum, e que, portanto, devem ser planejadas em conjunto. Essa reflexão demonstra que a problemática da participação nos processos políticos e de planejamento urbano está implícita na própria ideia de cidade, constituindo-se como uma questão central que perpassa as discussões sobre os métodos de planejamento territorial até hoje.

Planejar é um conceito que remete ao futuro, relacionado à noção de previsão. No planejamento urbano, é preciso prever cenários e elaborar estratégias para atingir os objetivos estabelecidos para a cidade (SOUZA, 2006). Como a atividade de planejar envolve o estudo e a intervenção em um contexto de incerteza, conflitos e disputas, pode-se dizer que a complexidade do planejamento urbano refere-se diretamente à cidade.

Assim, a cidade configura-se muito mais como um resultado dos conflitos socioeconômicos do que como um produto democrático que pressupõe a participação. Frente aos conflitos sociais e, sobretudo, contrariando os métodos tradicionais de planejamento onde geralmente o Estado é o responsável pela produção de planos e pelas intervenções urbanas (práticas do tipo topdown, alinhadas com a lógica tecnocrática), diversas iniciativas populares surgem buscando autonomia e diálogo com o poder público para debater a cidade de maneira colaborativa (práticas do tipo bottom-up, que emergem dos cidadãos).

Superando barreiras e criando novas possibilidades de atuação (ASCHER, 2010), as Tecnologias de Informação e Comunicação (TICs) criam novos espaços de troca e compartilhamento, conectando governantes e governados e provocando diversas transformações na cidade, "ampliando" o seu território (FIRMINO E DUARTE, 2008) a partir das tecnologias e das novas redes estabelecidas. Para investigar esta temática, este trabalho parte do seguinte questionamento: como as TICs estão sendo apropriadas em processos participativos contemporâneos no contexto brasileiro?

No intuito de debater sobre as possibilidades de utilização das TICs nos processos participativos é preciso considerar pontos positivos e negativos, tanto no modo de operar das ferramentas como também nas possíveis ameaças existentes nas redes (MENESES et al, 2019; REGATTIERI, 2019). A possibilidade de existência destas ameaças provoca sérios questionamentos sobre a validade dos processos participativos contemporâneos, grande parte realizados em ambientes virtuais. Esta pesquisa admite que as dificuldades enfrentadas nos processos participativos contemporâneos não são provocadas somente pelas tecnologias e que, portanto, é preciso investigar como as TICs podem contribuir para resolução desses problemas no intuito de aumentar a eficiência dos processos. Nesse sentido, os objetivos deste trabalho são: 1) Realizar um levantamento de dispositivos virtuais de participação para analisar sua utilização nos processos participativos contemporâneos; 2) Identificar e sistematizar os principais problemas dos processos participativos contemporâneos.

\section{METODOLOGIA DE TRABALHO}

Na intenção de compreender como funciona o processo de interação proporcionado pelos dispositivos de participação que operam a partir de Tecnologias de Informação e Comunicação (TICs), esta pesquisa parte de um levantamento bibliográfico sobre processos participativos, contemplando métodos de participação tradicionais e contemporâneos (BORDENAVE, 1983; ARNSTEIN, 1969; ALEXANDER, 1998; PEREIRA, 2017; SOUZA, 2006; ROCHA e PEREIRA, 2011; 
GOMES, 2011), e sobre cidade contemporânea e tecnologias, buscando compreender as transformações na cidade e no planejamento a partir do desenvolvimento tecnológico (ASCHER, 2010; BATTY, 2011; CASTELLS, 1999; FIRMINO, 2011; FIRMINO e DUARTE, 2008; LEMOS, 2016; LÉVY; 1999; MENESES, 2017; MENESES et al, 2019; MOROZOV, 2019).

A segunda parte do trabalho consiste no levantamento e na classificação de dispositivos virtuais de participação, baseando-se inicialmente na pesquisa realizada por Meneses (2017). Foi realizada uma busca em sites, blogs, redes sociais e portais governamentais para selecionar iniciativas apresentadas como participativas. Da lista de iniciativas pesquisadas, este trabalho apresenta e analisa seis exemplos. Foram estabelecidos parâmetros de análise para caracterizar a origem (instituição ou organização mantenedora), o objetivo (intuito maior de funcionamento), as ferramentas (possibilidades de uso do dispositivo) e o tipo de conexão estabelecido pelos dispositivos com o usuário (MENESES, 2017; VIEIRA, 2008).

Ao final, no intuito de atingir os objetivos almejados, foi realizada uma reflexão sobre a contribuição dos dispositivos virtuais nos processos participativos, amparando-se em análises de outros autores sobre as dificuldades de realização de processos participativos tradicionais (LUCHMANN, 2003; PEREIRA, 2017; SOUZA, 2006) e contemporâneos (ROCHA e PEREIRA, 2011; GOMES, 2011, MENESES et al, 2019), visando discutir sobre os pontos positivos e negativos dos dispositivos virtuais nos processos participativos.

\section{DA ESCADA DA PARTICIPAÇÃO ÀS TECNOLOGIAS DE INFORMAÇÃO E COMUNICAÇÃO}

A necessidade de existir participação em processos decisórios sobre o planejamento do espaço ou sobre o uso de recursos públicos parece ser reconhecida por todos os setores da sociedade, inclusive como condição essencial para o êxito do planejamento urbano, por exemplo. No entanto, o atual contexto de elaboração de políticas, projetos e planos diretores no Brasil demonstra que a falta de participação ainda é um dos maiores obstáculos para a democratização desses processos (PEREIRA, 2015).

A sociedade está organizada a partir grupos sociais promotores de interação entre seus membros e, neste sentido, a participação manifesta-se como uma característica intrínseca do ser humano, uma necessidade de sentir-se parte, de atuar de forma coletiva na construção de um objetivo comum (BORDENAVE, 1983). 0 debate sobre a participação adquiriu cada vez mais importância ao longo da história e, considerando o atual contexto político brasileiro, tornou-se um debate profundamente influenciado pela crise de representatividade e pelo descrédito das instituições. A realização de processos de planejamento urbano sem a participação dos habitantes da cidade enfraquece as dimensões democráticas e prolonga a situação de segregação presente na sociedade.

Um fato que agrava a contradição presente nos processos de planejamento urbano é que, segundo o Estatuto da Cidade (BRASIL, 2001), a participação é obrigatória na elaboração de planos diretores municipais. No entanto, estes processos ocorrem sem o conhecimento da população, ou a partir de ações de cooptação, nas quais ocorre uma participação simulada e o debate é conduzido para decisões acertadas previamente com base em interesses privados.

Sherry Arnstein propôs uma classificação referente a participação popular chamada de "escada da participação" (ARNSTEIN, 1969), baseando-se em diversos processos ocorridos nos Estados Unidos na década de 1970 e descrevendo um contexto bastante semelhante ao brasileiro. A ideia de Arnstein, que influencia o pensamento de planejadores e estudiosos da cidade até hoje, é uma crítica aos processos promovidos pelo Estado, que geralmente são rotulados de participativos mas ocorrem sem uma participação popular genuína. A crítica da autora permanece atual pois, dada a situação de crise pela qual passa a democracia contemporânea, 
continuam ocorrendo processos sem nenhum comprometimento com as demandas populares. A escada da participação é composta, indo do menor para o maior grau de participação, das seguintes classificações: Manipulação, Terapia, Informação, Consulta, Pacificação, Parceria, Delegação de poder e Controle cidadão.

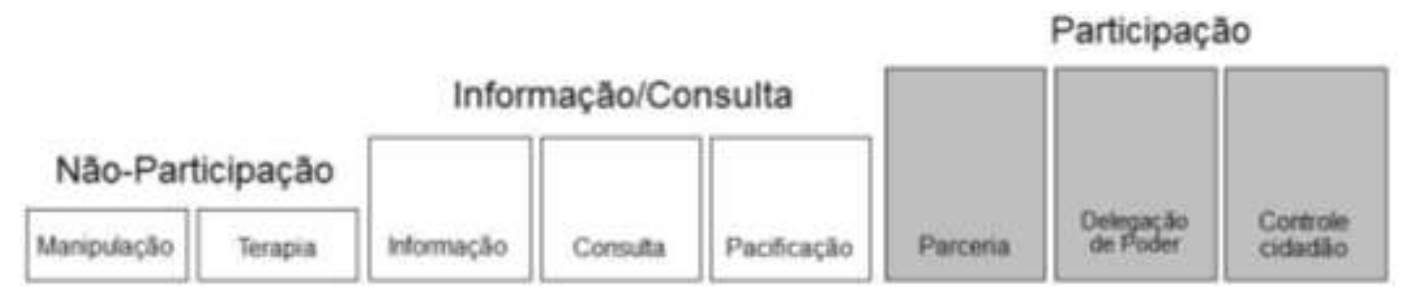

Segundo a autora, os dois primeiros degraus (Manipulação e Terapia) são considerados exemplos de não-participação. Os níveis de informação e consulta abrem um campo maior de possibilidades, porém ainda com diversas restrições pois, apesar de proporcionar o diálogo, não há certeza sobre a compreensão do posicionamento da população no processo decisório. O patamar denominado de Pacificação (entendido também como apaziguamento) consiste em uma evolução dos dois últimos degraus descritos, com a possibilidade de maior abertura de diálogo. Somente os três últimos degraus representam casos de participação popular genuína, onde é expresso o verdadeiro poder cidadão. No primeiro caso, a população pode realizar uma "parceria que lhes permita negociar de igual para igual com aqueles que tradicionalmente detém o poder" (ARNSTEIN, 1969). Nos dois últimos degraus, a população detém a maioria do poder nos processos decisórios ou detém o poder por completo.

O debate sobre novas formas de participação, contando com o esforço de grupos da sociedade civil e de movimentos sociais, obteve importantes conquistas ao longo do tempo, tais como: a Constituição Federal de 1988, conhecida como constituição cidadã; o Estatuto da Cidade em 2001, que tornou obrigatória a participação na elaboração de planos diretores; a criação do Ministério das Cidades em 2003, que trouxe a política urbana para o centro do debate sobre o desenvolvimento das cidades. Diversas práticas alternativas desenvolveram-se como consequência da crescente necessidade de engajamento popular, fazendo emergir novas ferramentas de participação que, mais recentemente, passaram a apresentar-se alinhadas com as novas possibilidades das Tecnologias de Informação e Comunicação. No entanto, mesmo utilizando-se de novas ferramentas, os canais de participação contemporâneos permanecem tendo o objetivo de proporcionar autonomia e cidadania para a população.

Além de proporcionar novas possibilidades de participação, as tecnologias computacionais de base digital, principalmente através de aplicativos móveis, passaram a proporcionar novas formas de expressão, novas linguagens que modificam completamente o modo de vida contemporâneo e produzem um "dilúvio de informações" (LÉVY, 1999).

Esta condição de ubiquidade das Tecnologias de Informação e Comunicação (CASTELLS, 1999) transforma a cidade e a relação das pessoas com o espaço urbano, e faz emergir conceitos como o de ciberespaço, definido por Pierre Levy como "rede" (LÉVY, 1999) e por André Lemos como o ambiente telemático que abriga os aplicativos e as redes sociais, "se confunde com a Internet, mas não está a ela limitado" (LEMOS, 2016). Rodrigo Firmino interpreta esta situação defendendo a ideia de uma cidade "ampliada" pelas tecnologias telemáticas, onde o espaço torna-se híbrido e é necessário "reconceitualizar as relações entre espaço, tempo e tecnologia" (FIRMINO, 2011. p.8).

Batty explana sobre a evolução da noção de cidade, antes tratada como sistema mecânico (conjunto de partes que interagem em equilíbrio, organizada de cima para baixo), e atualmente mais próxima da noção de organismo biológico (não está sempre em equilíbrio), que evolui de baixo para cima, como "produto de milhões de decisões individuais e em grupo" (BATTY,
Figura 1: Escada da Participação.

Fonte: Elaborado por Meneses (2017) a partir de Arnstein (1969). 
2011), noção que atesta a relevância e a potência da participação dos cidadãos na construção da cidade, compreendida como produto coletivo.

É preciso considerar, portanto, que os dispositivos de comunicação contemporâneos de fato permitem novas formas de participação, porém, a internet e suas ferramentas, bem como os aparelhos conectados através da rede, não constituem, sozinhos, uma garantia de participação. E ainda, quando esta participação de fato pode ser verificada, não é possível ter certeza da sua qualidade ou dos seus impactos. Segundo Gomes (2011), apesar disto, é possível que existam alternativas de auxílio e incremento para a participação através da internet, dividindo-a em instrumental e essencial a partir do seu uso específico (GOMES, 2011. p 20). 0 usuário, por exemplo, que utiliza um e-mail para fazer contatos políticos, apenas trocou a carta pelo e-mail, substituindo a forma de comunicar-se e fazendo com que, neste caso, a internet seja somente instrumental. Porém, quando o usuário lança mão de ferramentas como blogs, Facebook, Twitter, ocorre que a internet - tal como especificou Gomes (2011) - é essencial pois estes recursos, embora sejam também formas de comunicação tal qual as formas tradicionais, guardam possibilidades de comunicação e interação desenvolvidas especificamente para estas ferramentas. A questão mais relevante levantada por essas definições reside no debate sobre os novos mecanismos de interação trazidos pela Internet e pelos novos meios de comunicação e as suas possibilidades para a participação.

Entretanto, em um estudo sobre as redes sociais virtuais enquanto espaços de participação, Rocha e Pereira (2011) atestam que as mídias sociais "não vêm sendo predominantemente utilizadas para constituir espaços virtuais de interação capazes de incluir o cidadão como ator ativo na tomada de decisões. Pelo contrário, em geral, elas têm sido utilizadas pelo Estado para um tipo de comunicação unidirecional" (ROCHA e PEREIRA, 2011). A condição de subutilização dessas ferramentas por parte do Estado é um reflexo do que ocorre, grande parte das vezes, com as ferramentas de participação tradicionais - ou que não utilizam tecnologias de base digital. Conforme observado no estudo de Arnstein (1969), os diversos tipos de participação demonstram que nem sempre as "rotinas participativas" (SOUZA, 2006) vão além da fase de informação. No entanto, a divulgação de informações relativas à gestão e suas ações é um passo importante para conquistar um patamar de controle social.

\section{DISPOSITIVOS VIRTUAIS DE PARTICIPAÇÃO: CONECTIVIDADE E CONEXÃO}

Para analisar alternativas de participação por meio das TICs, as iniciativas aqui apresentadas foram definidas como Dispositivos Virtuais de Participação. Segundo o dicionário Michaelis On-line, dispositivo é "aquilo que determina, que ordena", e "Aquilo que contém ordem; norma, preceito, prescrição", portanto, compreende-se aqui os sites, aplicativos, plataformas, blogs como dispositivos que operam através de dimensões virtuais (a partir de tecnologias de informação e comunicação de base digital) e cujo objetivo é a participação popular em processos de interesse público e coletivo.

A partir do levantamento realizado e analisando a origem, os objetivos e as ferramentas de cada dispositivo, foi adotada a seguinte classificação em três tipologias: Dispositivos de Informação, Dispositivos de Mobilização e Ativismo e Dispositivos Didáticos e de Pesquisa (MENESES, 2017).

Os Dispositivos de Informação representam a tipologia mais tradicional e tem como exemplo os portais de informação governamentais, cujo objetivo principal é fornecer informações sobre o território (cidade, estado, país). Neste caso, são sites criados para divulgar informações da gestão municipal, estadual ou federal e funcionam, na maior parte das vezes, apenas como ambientes de marketing político, exibindo dados previamente selecionados para construir a imagem desejada sobre a gestão pública. No caso de serem mantidos por iniciativas da sociedade sem vínculos governamentais, assumem um papel de apoio ao controle social 
quando fornecem informações estratégicas para os cidadãos. 0 objetivo desse tipo de dispositivo está relacionado ao compartilhamento de informações para que o cidadão acompanhe os acontecimentos e possa agir. No entanto, nem sempre há espaço para interação com o usuário. Mesmo assim, configura-se como uma iniciativa importante pois o acesso à informação é o primeiro passo do processo participativo.

Um dos exemplos desta tipologia, o Fortaleza em Mapas (https://mapas.fortaleza.ce.gov.br/), elaborado pelo Instituto de Planejamento de Fortaleza, é uma plataforma colaborativa de mapas abertos para inserção de dados sobre a cidade. 0 usuário deve entrar no site do projeto, escolher uma legenda temática na qual se classifica a informação que será mapeada (Espaços de lazer e convívio, Violência, Acessibilidade, Cultura e memória, Risco a saúde, Economia, Meio ambiente) e inserir os dados com uma breve descrição. 0 sistema recebe os dados fornecidos pelo usuário e gera relatórios periodicamente. Porém, nem todos os dados são utilizados para fins de planejamento e não existe um controle exato para selecionar os dados relevantes e otimizar o serviço. Neste caso, a única possibilidade de interação entre o usuário e a prefeitura é a seção "fale conosco", além da própria atividade de inserção de dados urbanos (ocorrências, buracos nas ruas, pontos de alagamentos, etc.). Porém, conforme Rocha e Pereira (2011) descrevem, a maioria dos portais do governo são espaços de comunicação unidirecional, fato percebido na pesquisa de Meneses (2017) sobre o Fortaleza em Mapas, quando aponta que a informação emitida pelo cidadão não tem nenhuma garantia de divulgação na forma de dado aberto na plataforma.

Outro exemplo de Dispositivo de Informação é o Observatório Cidadão de Piracicaba (http://www.observatoriopiracicaba.org.br/), uma plataforma criada por um conjunto de entidades públicas e privadas com o intuito de compartilhar informações de interesse do cidadão na esfera municipal. Intitulando-se como uma ferramenta de controle social, o observatório reúne informações divididas nos seguintes temas: Meio Ambiente, Metas, Participação Social e Transparência Pública. Os dados são apresentados sob a forma de indicadores construídos a partir de fontes diversas, permitindo ao cidadão realizar análises sobre a construção e implementação de políticas públicas do município. O Observatório de Piracicaba também só permite a interação com os usuários do Portal através do "fale conosco" e não apresenta os resultados ou feedbacks desse diálogo. A plataforma, portanto, apenas se propõe a fornecer informações e fontes para que o cidadão assuma uma conduta ativa em outro espaço, ou seja, configurando-se como um ambiente de coleta e compartilhamento de informações.

A segunda tipologia, Dispositivos de Mobilização e Ativismo, também pode ser chamada de "rede" pois fornece aos seus usuários a possibilidade de se reunir em grupos para criar mobilizações e também permite conectar-se com tomadores de decisão para exigir feedback sobre processos em andamento. A transformação da conduta de cidadão passivo, apenas consumidor de informações, para a conduta de cidadão ativo, que se integra em um movimento de mobilização e ativismo, é possibilitada a partir da mudança de relação entre portal e usuário. Os objetivos deste tipo de dispositivo são relativos às ações concretas dos cidadãos, como por exemplo, criar petições e abaixo-assinados online (apenas modificando a forma de coletar assinaturas mas mantendo as intenções originais), ou mesmo propor projetos de lei de iniciativa popular com base no número de usuários favoráveis.

Um dos exemplos desta tipologia é o Nossas (https://www.nossas.org/), que iniciou os trabalhos chamando-se "Nossas Cidades". Definindo-se como um laboratório de ativismo, uma organização apartidária e sem fins lucrativos, o Nossas propõe dar voz às demandas dos cidadãos através de uma rede de mobilização e ativismo em diversas cidades do Brasil. Além disso, a iniciativa também atua como uma incubadora, promovendo capacitações e treinamentos e fornecendo suporte a fim de que organizações a nível municipal (Meu Rio, 
Minha Sampa, Meu Recife) se mobilizem e atuem prol das causas locais com uma rede de voluntários. 0 Nossas, através das suas redes municipais criou e geriu algumas ferramentas, tais como a Panela de Pressão (para fazer pressão popular nos tomadores de decisão), a Legislando (para apoiar e promover projetos de lei de iniciativa popular) e a De Guarda (para possibilitar "vigílias" virtuais em edificações ou locais ameaçados de demolição ou ocupação indevida pelo poder público). Uma característica diferenciada do Nossas é a prestação de contas aberta que é realizada na seção "Transparência" mediante o compartilhamento de auditorias contábeis e do relatório anual para livre conferência.

Outro caso de Dispositivo de Mobilização e Ativismo é o Change.org (http://www.change.org/), uma plataforma virtual de construção de abaixo-assinados sobre diversos temas de interesse público que apoia iniciativas em várias partes do mundo. 0 sistema funciona na forma tradicional de um abaixo-assinado, porém, com o auxílio da internet e da inteligência artificial, a plataforma faz com que o abaixo-assinado seja visto por um público específico de pessoas que possuem interesse no tema e também contribui para que o resultado chegue aos tomadores de decisão, pressionando-os e influenciando sua conduta.

A terceira e última tipologia de dispositivo, os Dispositivos Didáticos e de Pesquisa, assemelhase à tipologia Dispositivos de Informação, porém, inserindo mecanismos de interatividade e permitindo análises, comparações e configurações na exibição dos dados. É importante observar que, a partir do levantamento realizado, esta tipologia de dispositivo, na maioria das vezes, possui uma atuação de caráter interescalar, diferente das outras tipologias que geralmente se concentram na escala local. Muitas vezes criados através da associação de empresas e instituições particulares, esses dispositivos, embora promovam compartilhamento de informações para os cidadãos, também possuem uma preocupação didática e de pesquisa. Além de fornecer dados para o usuário, esses portais oferecem mecanismos interativos de organização e análise desses dados, adicionando mais complexidade na construção de cenários e no agrupamento de informações.

Um exemplo desta tipologia é a Alerta Democrática (http://alertademocratica.org/), uma plataforma criada em 2014 a partir do emergente contexto político mundial mediante a reunião de líderes de todos os países da América Latina para a criação de cenários, prevendo transformações na democracia até o ano de 2030. Iniciativa do Instituto Reos e apoiada por instituições internacionais como Fundação Ford e Fundação Avina, a Alerta Democrática constrói previsões baseadas em fatos e destaca possibilidades e desafios democráticos para o futuro. Esse contexto é apresentado em um exercício de construção de quatro cenários distintos: "Democracia em Transformação", "Democracia em Tensão", "Democracia em Mobilização" e "Democracia em Agonia". Utilizando-se da metodologia de Planejamento de Cenários Transformadores, a plataforma apresenta questões como a falta de representatividade, descrença da população nas instituições, conflitos socioespaciais, novos canais de mobilização por meio da tecnologia, corrupção e repressão policial e desenvolvimento de novas formas de participação e colaboração. A intenção da plataforma é apresentar os cenários como produto provocativo e em tom de alerta para que os cidadãos tenham consciência e se mobilizem sobre os caminhos possíveis da democracia latinoamericana e para embasar a construção de agendas e condutas nos âmbitos políticos, acadêmicos e sociais.

Outra iniciativa classificada como Dispositivo Didático e de Pesquisa é o Instituto Update Laboratório de Inovação Política na América Latina (https://www.institutoupdate.org.br/). É fruto da sociedade civil e trabalha com pesquisa e fomento de iniciativas de inovação política, mobilização e participação na América Latina - geralmente com uso da internet - utilizando como background o contexto sociopolítico do continente. 0 resultado é um panorama de projetos que a plataforma pesquisa e fomenta, tais como: Emergência política de mulheres (pesquisa realizada com mulheres eleitas para cargos públicos), Formação Democrática 
(capacitações para equipes de campanhas políticas inovadoras e de baixo orçamento), Gabinete da inovação (grupos de debate com gabinetes atuantes na inovação política), Emergência política tendências (levantamento e classificação de 700 iniciativas de inovação política da América Latina), dentre outros.

O Instituto Update foi criado em 2015 apenas com a pesquisa sobre as iniciativas de inovação política da América Latina e atualmente recebe doações de pessoas físicas e de instituições (como BMW Foundation, Fundação Ford e Fundação Avina), atuando com o objetivo de gerar visibilidade para as ações pesquisadas e também impulsionar a viabilidade do ecossistema de inovação política latinoamericano.

Para compreender a relação entre os objetivos dos dispositivos e sua utilização, é essencial questionar-se sobre a conexão que eles representam para cidadãos e governantes. Segundo Vieira (2008), parâmetros evolutivos são aqueles que expressam a temporalidade de qualquer sistema. Encarando o processo de planejamento participativo como um sistema composto de diversas partes relacionadas, dois destes parâmetros são relevantes para esta análise: conectividade e estrutura. Segundo o autor, a conectividade é a capacidade dos elementos de um sistema de estabelecer conexões ou relações entre si. Já estrutura ocorre quando as relações são estabelecidas, é a conexão de fato (VIEIRA, 2008). Ou seja, a conectividade representa a possibilidade, a estrutura representa o fato ocorrido. Neste sentido, os novos espaços virtuais de produção e compartilhamento de informações estabelecidos pelo uso das TICs representam possibilidades de conexão entre atores sociais, porém não representam estas conexões de fato.

Os dispositivos virtuais de participação apresentados operam sobre a conectividade ampliando as possibilidades de efetivação de novas conexões, em muitos casos, com agilidade e eficiência. Algumas vezes também possibilitam tipos de relações nunca antes experimentadas, atributo próprio da ubiquidade das TICs. Porém, é preciso admitir que o estabelecimento de um canal de relação entre um cidadão e um gestor não significa necessariamente a construção de uma atividade democrática e participativa de planejamento da cidade. Nos casos nos quais a conexão é de fato estabelecida, a análise deve ocorrer sobre a qualidade e a efetividade do contato proporcionado. Segundo Denbigh (1975 apud VIEIRA, 2008) as conexões podem ser ativas, quando permitem o intercâmbio de informações; indiferentes, quando são indiferentes a este intercâmbio; e podem ser opostas ou contrárias, quando bloqueiam o transporte de informações. Esta classificação corrobora com os tipos de dispositivos apresentados anteriormente.

Os dispositivos do tipo Mobilização e Ativismo estabelecem conexões do tipo ativas, tais como as redes sociais virtuais que funcionam como espaços democráticos de comunicação multidirecional. Os dispositivos do tipo Didáticos e de Pesquisa podem estabelecer conexões do tipo indiferente, visto que muito deles são indiferentes - e muitas vezes até estanques - na transmissão das informações que exibem. Nos dispositivos do tipo Informação, no caso específico dos portais governamentais, o fluxo de informações é, na maioria das vezes, unidirecional. Dessa forma, as conexões que estes dispositivos estabelecem são do tipo opostas ou contrárias. A seguir está um quadro síntese sobre os dispositivos virtuais de participação, suas características e sua classificação quanto à tipologia e ao tipo de conexão. 


\begin{tabular}{|c|c|c|c|c|}
\hline $\begin{array}{l}\text { tipologia e } \\
\text { conexão }\end{array}$ & dispositivo & origem & objetivo & ferramentas \\
\hline \multirow{2}{*}{$\begin{array}{l}\text { Informação } \\
\text { conexão } \\
\text { oposta ou } \\
\text { contrária }\end{array}$} & $\begin{array}{l}\text { Fortaleza em } \\
\text { Mapas }\end{array}$ & $\begin{array}{l}\text { Prefeitura de } \\
\text { Fortaleza }\end{array}$ & $\begin{array}{l}\text { Coletar e divulgar } \\
\text { informações } \\
\text { georreferenciadas } \\
\text { sobre a cidade }\end{array}$ & $\begin{array}{l}\text { Mapeamento de ocorrências } \\
\text { urbanas (dados geográficos)e } \\
\text { disponibilização de mapas } \\
\text { temáticos para o cidadão }\end{array}$ \\
\hline & $\begin{array}{l}\text { Observatório } \\
\text { Cidadão de } \\
\text { Piracicaba }\end{array}$ & $\begin{array}{l}\text { Grupo da } \\
\text { sociedade } \\
\text { civil }\end{array}$ & $\begin{array}{l}\text { Divulgar informaçõese } \\
\text { indicadores sobrea } \\
\text { cidade }\end{array}$ & $\begin{array}{l}\text { Formulação e divulgação de } \\
\text { indicadores e cobertura de } \\
\text { processos da gestão pública }\end{array}$ \\
\hline \multirow{2}{*}{$\begin{array}{l}\text { Mobilização } \\
\text { e Ativismo } \\
\text { conexão ativa }\end{array}$} & Nossas & $\begin{array}{l}\text { Grupo da } \\
\text { sociedade } \\
\text { civil }\end{array}$ & $\begin{array}{l}\text { Agrupar cidadãos com } \\
\text { interesses em comum } \\
\text { para auxiliar em } \\
\text { mobilizações }\end{array}$ & $\begin{array}{l}\text { Panela de Pressão (pressionar } \\
\text { gestores), Legislando (lei de } \\
\text { iniciativa popular), De Guarda } \\
\text { (monitoramento de edificações) }\end{array}$ \\
\hline & Change.org & $\begin{array}{l}\text { Grupo da } \\
\text { sociedade } \\
\text { civil }\end{array}$ & $\begin{array}{l}\text { Estruturar petições online } \\
\text { fornecendomecanismos } \\
\text { de potencializaçãoe } \\
\text { divulgação }\end{array}$ & $\begin{array}{l}\text { Petições online, abaixo } \\
\text { assinado, listas de assinaturas, } \\
\text { impulsionamento de campanhas } \\
\text { com inteligência artificial }\end{array}$ \\
\hline \multirow{2}{*}{$\begin{array}{l}\text { Didáticos e } \\
\text { de Pesquisa } \\
\text { conexão } \\
\text { indiferente }\end{array}$} & $\begin{array}{l}\text { Alerta } \\
\text { Democrático }\end{array}$ & $\begin{array}{l}\text { Instituto } \\
\text { Reos }\end{array}$ & $\begin{array}{l}\text { Informar sobre o futuro } \\
\text { da democracia latino } \\
\text { americana para fomentar } \\
\text { novas alternativas }\end{array}$ & $\begin{array}{l}\text { Criação e intepretação de } \\
\text { cenários futuros com previsões } \\
\text { realizadas a partir dos dados } \\
\text { atualizados }\end{array}$ \\
\hline & $\begin{array}{l}\text { Instituto } \\
\text { Update }\end{array}$ & $\begin{array}{l}\text { Grupo da } \\
\text { sociedadel } \\
\text { fundações }\end{array}$ & $\begin{array}{l}\text { Pesquisar e fomentar } \\
\text { iniciativas de inovação } \\
\text { política na América } \\
\text { Latina }\end{array}$ & $\begin{array}{l}\text { Disponibilização de informações } \\
\text { sobre as iniciativas } \\
\text { pesquisadas, publicações } \\
\text { informativas }\end{array}$ \\
\hline
\end{tabular}

Figura 2: Caracterização e classificação dos dispositivos virtuais de participação.

Fonte: Adaptado de Meneses (2017).

Pode ser observado que todos os dispositivos analisados trazem algum tipo de contribuição em diferentes etapas do processo participativo dado que apresentam possibilidades de interação (conectividade) entre governantes e governados ou permitem a criação de espaços de debate sobre questões importantes relativas a população. Porém, é preciso considerar que, assim como definido por Arnstein (1969) sobre processos de cooptação ou terapia, os espaços virtuais de participação também podem ser corrompidos. Como o formato foi transformado (do espaço físico para o espaço virtual), o processo parece diferente e, muitas vezes, idôneo, mas permanece com problemáticas muito semelhantes às verificadas nas metodologias tradicionais. Por esse motivo, como dito anteriormente, é essencial refletir sobre a qualidade da conexão estabelecida.

Este panorama demonstra, ao estudar sobre as novas possibilidades trazidas pelas TICs, a exigência de permanecer com uma visão crítica sob pena de aderir a uma perspectiva enviesada sobre o assunto. Não se pode ignorar a falibilidade dos dispositivos estudados, bem como o largo conjunto de fatores que influenciam opiniões e ações nos espaços virtuais. São constantes os questionamentos sobre a legitimidade da democracia exercida nos espaços virtuais, por isso, processos desta natureza devem considerar as limitações impostas pelo próprio espaço virtual, tais como a falsa identidade, a manipulação e falsificação de dados e mídias (MENESES et al, 2019; REGATTIERI, 2019).

\section{PROCESSO PARTICIPATIVO: NOVAS TECNOLOGIAS, VELHOS PROBLEMAS}

Para responder ao questionamento inicial, é necessário refletir sobre as contribuições das tecnologias em fases específicas do processo participativo, buscando perceber quais entraves permanecem mesmo com uso de ferramentas digitais. Para realizar uma análise aprofundada, este trabalho propõe que o tema seja interpretado a partir de três perspectivas diferentes: os problemas da ferramenta (relativos ao modo de funcionamento das ferramentas amparadas 
nas TICs e as influências externas); os problemas do processo participativo (relativos à metodologia de trabalho) e problemas dos cidadãos (relativos a aspectos socioeconômicos e políticos).

Sobre os problemas da ferramenta (TICs), o fator mais importante a ser contemplado no debate é a exclusão digital, grande entrave para o desenvolvimento de populações em diversas partes do mundo. De acordo com a Organização das Nações Unidas, um dos objetivos para o milênio é "Desenvolver uma parceria global para o desenvolvimento", apresentando como uma das metas a ampliação do acesso às tecnologias de informação e comunicação. Esta necessidade é confirmada por um estudo que descreve um cenário no qual "menos de um terço da população no mundo em vias de desenvolvimento está online, em comparação com os 78 por cento no mundo desenvolvido" (NAÇÕES UNIDAS, 2015). Ao mesmo tempo, no relatório de 2015 já é percebido um aumento de pessoas que possuem telefone móvel e internet.

Segundo Marques (2014), os estudos relativos aos impactos das tecnologias digitais sobre a democracia apresentam dois equívocos: o determinismo tecnológico e a ingenuidade nas análises sobre o poder das instituições e agentes representativos. Compreende-se como determinismo tecnológico a crença de que a tecnologia provoca transformações na sociedade e não o contrário, ou a percepção da influência da tecnologia como algo sempre positivo, ignorando os mecanismos de manipulação e poder que se apresentam na forma de "inovação tecnológica" (CASTELLS, 1999. p. 64). Esta ideia também é exemplificada por Morozov (2019) em sua análise crítica sobre a construção do conceito de smart city, quando o autor aponta indícios da ligação do termo "smart" à estratégia de grandes corporações para ampliação dos lucros com a inserção de tecnologia nas cidades, tornando-as "inteligentes" (MOROZOV, 2019).

A exclusão digital não está somente na impossibilidade de acesso a um aparelho smartphone ou a um computador com internet, mas também na falta de conhecimento sobre as ferramentas. Por fim, admitindo conectividade e conexão como conceitos diferentes (VIEIRA, 2008), é essencial compreender que o acesso do usuário à ferramenta não garante a sua participação efetiva pois é necessário um engajamento do cidadão para integrar o processo participativo. (MENESES, 2017).

Outro problema da ferramenta é a falta de legitimidade das redes de participação, muitas vezes ocasionado pela influência das instituições nos espaços virtuais (MARQUES, 2014). Diversos canais são criados com o intuito participativo e no entanto, servem apenas aos interesses das empresas que os patrocinam (MENESES et al, 2019) e, em outros casos, são criados por entes públicos somente para cooptação, como os portais governamentais, por exemplo, que promovem apenas uma comunicação unidirecional (ROCHA e PEREIRA, 2011). Além disso, são conhecidos diversos casos da utilização de estratégias de manipulação tais como perfis falsos, robôs, disparo em massa de notícias falsas, softwares de edição audiovisual utilizados para produção de fake news, recursos que influenciam o comportamento das pessoas mediante mineração, modelagem de dados e manipulação de tendências, modificando sobremaneira as redes existentes e colocando em cheque a credibilidade desses espaços (REGATTIERI, 2019; RUEDIGER, 2017; MENESES et al., 2019).

Sobre os problemas do processo participativo, devem ser consideradas algumas condições favoráveis à participação popular de qualidade em políticas públicas ou na elaboração de Planos Diretores (PEREIRA, 2017; LUCHMANN, 2003). As condições para que ocorra a participação popular em políticas públicas - definidas por Luchmann (2003) - são a tradição associativa, a vontade política e o desenho institucional. Pereira (2017) acrescenta mais uma condição: o comprometimento dos técnicos envolvidos com o princípio participativo. 0 autor também destaca a importância de considerar a influência dos fatores próprios do território em estudo (contexto local). A imagem de um processo participativo é, muitas vezes, a de um 
processo lento, complexo, oneroso e ineficiente para a escala da cidade, principalmente pela quantidade de atores participantes e a dificuldade de estabelecer acordos.

Também é preciso considerar como problema do processo a adequação das ferramentas digitais no âmbito institucional, sua aderência no sistema de planejamento adotado e sua eficiência na resolução dos problemas existentes (MENESES, 2017). Este fator atesta a importância da dimensão institucional, seja no comprometimento da gestão pública com o processo participativo, seja no desenvolvimento de ferramentas para possibilitar processos mais dinâmicos com feedback contínuo da população (ASCHER, 2010).

Segundo Souza (2006), podem ser identificados três tipos de obstáculos à participação popular. 0 primeiro deles é a cooptação, prática que transforma o processo participativo em "um instrumento de domesticação da sociedade civil por parte das forças políticas à frente do aparelho de Estado." (SOUZA, 2006. p. 410). 0 segundo obstáculo é definido pelo autor como a problemática da implementação (do processo), reunindo todas as dificuldades logísticas enfrentadas para a realização de um processo como esse, tais como incompetências gerenciais, conflitos políticos e ideológicos, pressão de grupos sociais influentes (SOUZA, 2006. p. 410).

Sobre os problemas dos cidadãos, compreende-se principalmente as dificuldades socioeconômicas, fator que impede a população de ter tempo livre para participar dos processos (MENESES, 2017). Esta mesma questão também é apontada por Souza (2006) como a problemática da desigualdade, referente as dificuldades enfrentadas pelas populações de baixa renda para participar voluntariamente de reuniões e assembléias promovidas em prol de questões coletivas. Essas dificuldades vão desde as privações financeiras até os problemas de disponibilidade de horários que não concorram com o expediente de trabalho. 0 autor cita ainda dificuldades ligadas a autoconfiança dos cidadãos envolvidos, que nem sempre acreditam no potencial de sua participação no processo (SOUZA, 2006. p. 411). Além disso, é preciso considerar também como problema dos cidadãos a falta de engajamento político, em grande parte motivada pelo contexto atual de descrédito das instituições, falta de confiança nos processo políticos e participativos (MENESES, 2017). Abaixo está um quadro síntese com os problemas apontados pelos diversos autores.

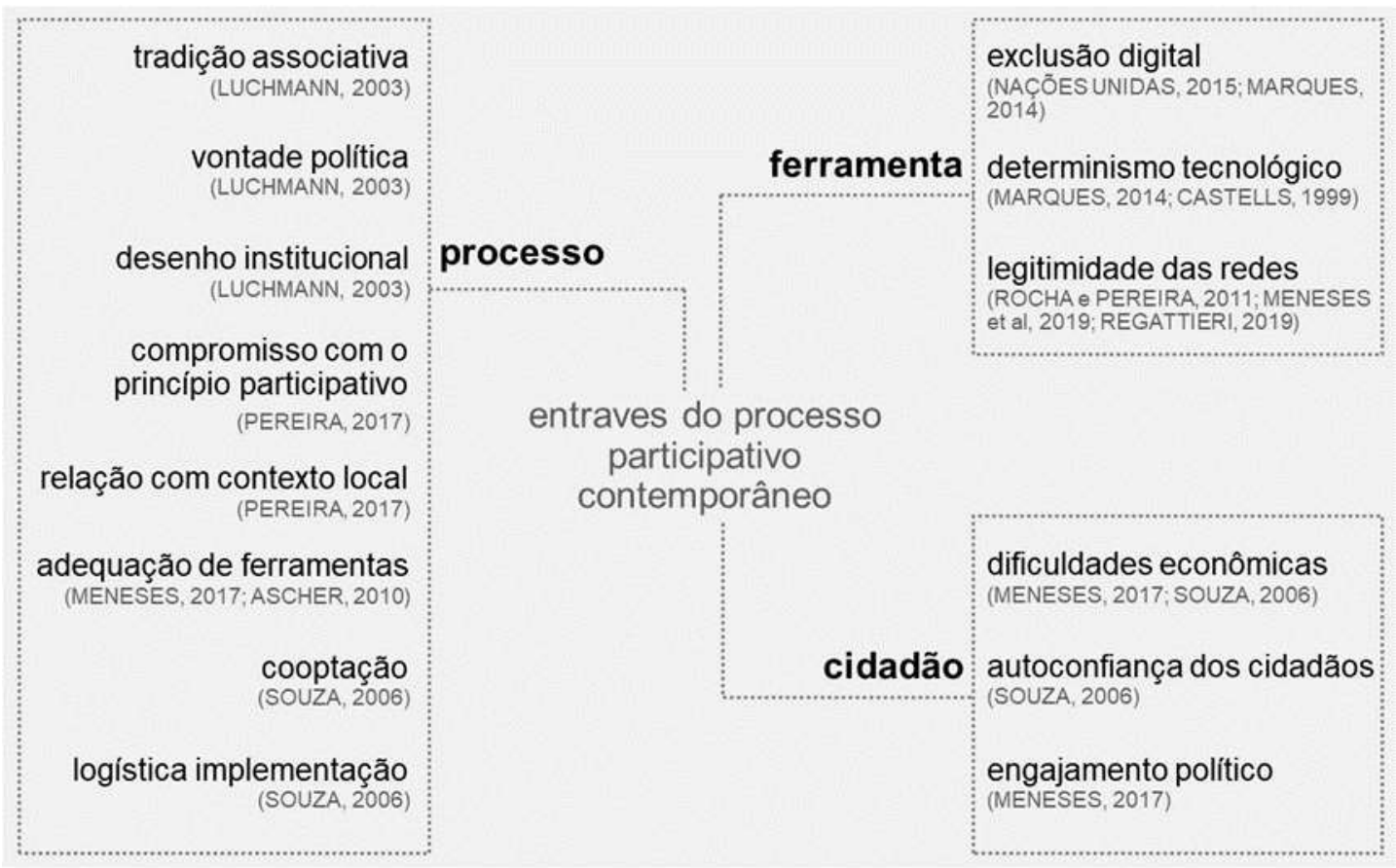

Figura 3: Síntese dos problemas do processo participativo contemporâneo.

Fonte: Elaborado pelos autores. 
Ao observar o quadro-síntese é possível perceber que há um contexto de profunda transformação nos processos participativos com a inserção crescente das Tecnologias de Informação e Comunicação. No entanto, apesar de as relações e interações nesses processos terem sido modificadas, é notável que os entraves existentes nos métodos tradicionais permanecem nos processos que utilizam os dispositivos virtuais. Além disso, é importante ressaltar a influência de fatores e agentes externos ao processo, muitas vezes no âmbito político e econômico, alterando o caráter dos espaços participativos.

\section{CONSIDERAÇÕES FINAIS}

Para concluir, retoma-se aqui o questionamento inicial: como as TICs estão sendo apropriadas em processos participativos contemporâneos no contexto brasileiro? Para responder a esta questão foi realizado um levantamento bibliográfico que apresentou um panorama mais aprofundado sobre a ubiquidade das TICs não só nos processos participativos, mas em todos os setores da sociedade, demonstrando a abrangência destes recursos e expondo seus conflitos, tais como a exclusão digital. A base teórica selecionada para amparar o estudo aqui apresentado aponta para novos paradigmas socioeconômicos, políticos e culturais que passam a influenciar também no planejamento urbano. Esta percepção inicia-se com o reconhecimento de novas possibilidades para a participação, debate essencial para a construção de cidades mais democráticas.

Sobre este tema, a partir da análise dos dispositivos pesquisados e da sistematização proposta para os problemas dos processos participativos contemporâneos, fica claro que os novos métodos guardam problemas muito semelhantes aos encontrados nos processos participativos tradicionais. Essa conclusão representa um grande desafio (ou a renovação do desafio seminal) para o planejamento urbano: Como construir cidades mais democráticas considerando o contexto de desigualdades e entraves políticos da sociedade? Mais do que compreender o desafio, é importante ter consciência da influência e do potencial das tecnologias neste processo e também das ameaças que elas podem representar.

Nesse sentido, é essencial admitir que, refutando uma perspectiva de determinismo tecnológico, as TICs não são responsáveis pela transformação e pelo engajamento das populações em prol de questões coletivas. Esse engajamento é provocado por fatores de ordem política e social que apenas são reproduzidos com fidelidade nos espaços virtuais. Ou seja, o espaço é o meio para que as transformações ocorram, influenciando de forma positiva ou negativa a depender do contexto. As Tecnologias de Informação e Comunicação não representam, portanto, a solução para os problemas encontrados nos processos participativos - e talvez adicionem mais complexidade a eles - mas devem ser encaradas como uma alternativa aos métodos tradicionais em busca de um urbanismo de dispositivos (ASCHER, 2010), objetivando monitorar o desenvolvimento da cidade em tempo real para planejar intervenções mais dinâmicas e construir espaços mais democráticos.

\section{Referências Bibliográficas}

ALEXANDER, Christopher. Urbanismo y Participación. Barcelona: Gustavo Gili, 1998.

ARNSTEIN, S. R. A ladder of citizen participation. Journal of the American Institute of Planners, v. 35, jul, p. 216-224: 1969.

ASCHER, François. Os novos princípios do urbanismo. São Paulo: Romano Guerra, 2010.

BATTY, Michael. Building a science of cities. J. Cities. Volume 29, Supplement 1, March 2012, Pages S9-S16. (2011), DOI: <http://dx.doi.org/10.1016/i.cities.2011.11.008>. 
BORDENAVE, J. E. D. O que é participação? São Paulo: Editora Brasiliense, 1983.

BRASIL. Lei n 10.257 de 10 de Julho de 2001 - Estatuto da Cidade. Brasília, 2001.

CASTELLS, Manuel. A era da Informação: Economia, sociedade e cultura. Volume 1: A sociedade em rede. São Paulo: Paz e Terra, 1999.

DISPOSITIVO. In: Dicionário Michaelis On-line. Disponível em: $<$ http://michaelis.uol.com.br/busca? $r=0 \& f=0 \& t=0 \&$ palavra=dispositivo $>$. Acesso em: 02 fev. 2020.

FIRMINO, Rodrigo José. Cidade Ampliada: desenvolvimento urbano e tecnologias de informação e comunicação. São Paulo: Hedra, 2011.

FIRMINO, R.; DUARTE, F. Cidade infiltrada, espaço ampliado. Arquitextos, São Paulo, 096.01, Vitruvius, maio 2008.2 Disponível em: <https://www.vitruvius.com.br/revistas/read/arquitextos/08.096/3408>. Acesso em: 13 jun. 2020.

GOMES, W. Participação política online: questões e hipóteses de trabalho. In: ROUSILEY, C. M. M.; GOMES, W.; Marques, F. P. J. A. (Org.). Internet e participação política no Brasil. Porto Alegre: Sulina, 2011.

LEMOS, André. Ciberespaço. In: 101 conceitos de arquitetura e urbanismo na era digital. Frederico Braida, Fernando Lima, Juliane Fonseca e Vinícius Morais. São Paulo: ProBooks, 2016.

LÉVY, P. Cibercultura. Tradução de Carlos Irineu da Costa. São Paulo: Editora 34, 1999.

LUCHMANN, L. H. H. Redesenhando as relações entre sociedade e Estado: o tripé da democracia deliberativa. Katálisis v. 6 n. 2 p. 165-168. Florianópolis, jul-dez, 2003.

MARQUES, Francisco Paulo Jamil Almeida. Democracia online e o problema da exclusão digital. Intexto, Porto Alegre, UFRGS, n. 30, p. 93-113, jul. 2014. Disponivel em: <https://seer.ufrgs.br/intexto/article/view/41269>. Acesso: 13 jun. 2020.

MENESES, Vítor Domício de. Participação na era da informação: uma análise do uso das TICs nos processos participativos. Dissertação (mestrado) - Universidade Federal do Ceará, Centro de Tecnologia, Programa de Pós-Graduação em Arquitetura e Urbanismo e Design. 118 f. Fortaleza, 2017.

MENESES, Vítor Domício de; CARDOSO, Daniel Ribeiro; BEIRÃO, José Nuno. Redes urbanas híbridas: conflitos na criação dos espaços virtuais de participação. In: RENA, Natacha; FREITAS, Daniel; SÁ, Ana Isabel; BRANDÃO, Marcela (orgs). 2o Seminário Internacional Urbanismo Biopolítico. Belo Horizonte: Associação Imagem Comunitária, 2019. 1108p.

MOROZOV, Evgeni; BRIA, Francesca. A cidade inteligente - Tecnologias urbanas e democracia. São Paulo: Ubu Editora, 2019.

NAÇÕES UNIDAS, Organização das. Relatório sobre os objetivos de desenvolvimento do milênio. Nova lorque: ONU, 2015. Disponível em: <http://abm.org.br/ods/wpcontent/uploads/2017/10/Relatorio-sobre-os-Objetivos-do-Milenio-2015.pdf>. Acesso em: 13 jun. 2020.

PEREIRA, Elson Manoel. Como anda a participação? As condições para elaboração de Planos Diretores Participativos. Revista Brasileira de Estudos Urbanos e Regionais, v. 19, n. 2 p. 235-250. Recife, maio-ago, 2017.

REGATTIERI, Lorena Lucas. BOTS COMO AGENTES DE EXPRESSÃO: Regime de visibilidades e o poder de criar redes. Contracampo, Niterói, v. 38, n.2, p. 130-149, ago./nov. 2019. Disponível em: <https://periodicos.uff.br/contracampo/article/view/28504/pdf>. Acesso em: 13 jun. 2020. 
Vítor Domício de Meneses domiciomeneses@yahoo.com.br

Daniel Ribeiro Cardoso danielcardoso@ufc.br
ROCHA, M. F.; PEREIRA, G. C. Mídias Sociais e espaços de participação. In: Anais do Simsocial - Simpósio em Tecnologias Digitais e Sociabilidade: Mídias Sociais, Saberes e Representações. Salvador, 2011. Disponível

SOUZA, Marcelo Lopes de. A prisão e a ágora: reflexões em torno da democratização do planejamento e da gestão das cidades. Rio de Janeiro: Bertrand Brasil, 2006.

VIEIRA, J. A. Ontologia: Formas de conhecimento. Arte e ciência uma visão a partir da complexidade. Fortaleza: Expressão Gráfica e Editora, 2008. 